\title{
Coflestato
}

\section{O papel social do bibliotecário voltado às pessoas trans: aproximações teóricas}

\author{
Guilherme Goulart Righetto \\ Mestre; Universidade Federal de Santa Catarina, Florianópolis, SC, Brasil; \\ rghtto@gmail.com \\ Miriam Figueiredo Vieira da Cunha \\ Doutora; Universidade Federal de Santa Catarina, Florianópolis, SC, Brasil; \\ vieiradacunha.miriam@gmail.com \\ Elizete Vieira Vitorino \\ Doutora; Universidade Federal de Santa Catarina, Florianópolis, SC, Brasil; \\ elizete.vitorino@ufsc.br
}

\begin{abstract}
Resumo: Este trabalho analisa, mediante revisão da literatura, o papel social do bibliotecário e da biblioteca voltado às pessoas trans. Ele enfatiza a competência em informação como prática social do bibliotecário, bem como aponta a inexpressividade, em âmbito brasileiro, das iniciativas voltadas para com a população trans e de lésbicas, gays, bissexuais e outros. Também reafirma a necessidade da participação, a partir de suas práticas profissionais, no progresso político, socioeconômico, informacional e de resistência das classes minoritárias, apontando o protagonismo social, o empoderamento, a liberdade e a emancipação como fatores necessários ao desenvolvimento pessoal, profissional e social dos indivíduos. Como resultados do estudo, apontam-se a urgência da adesão política bibliotecária frente às minorias sociais, devendo-se focalizar e priorizar nas abordagens sociais (inclusão, cidadania e inclusão digital), principalmente em países em desenvolvimento, como o Brasil. Concluise que o papel social bibliotecário deve possibilitar vivenciar, captar e buscar suprir as necessidades de informação do modo que lhe compete, ao mesmo modo em que as bibliotecas e as unidades de informação contemporâneas têm de se apresentarem criativas, inovadoras e livres de preconceitos, visando o êxito ao lidar com as complexidades humanas e tecnológicas.
\end{abstract}

Palavras-chave: Bibliotecário. Biblioteca. Pessoas trans. Minorias sociais. Competência em informação.

\section{Introdução}

Atualmente, atravessamos uma notória mudança de paradigma oriunda da proliferação dos meios de comunicação e de informação. A atual configuração da nossa sociedade transformou a informação num poderoso capital de cunho 
social, cultural e econômico. Ao mesmo tempo, o padrão social da contemporaneidade é predominantemente excludente e impulsiona-nos cada vez mais para o aumento das desigualdades sociais, econômicas, culturais e informacionais.

No referido contexto, as bibliotecas são vistas como instituições protagonistas da educação e do livre acesso à informação, contribuindo para a diminuição da exclusão social. Quanto aos bibliotecários, um de seus desafios, na contemporaneidade, é relativo ao papel que ele deve incorporar como agente transformador em relação à disseminação da informação em larga escala e para as mais variadas demandas (PIRES, 2012).

Seu fazer profissional torna-se diversificado, com novas rotinas incorporadas às suas funções. Para Cunha (2003), "Isto significa entender os novos papéis que surgem, as novas necessidades de informação e as novas formas de responder a estas necessidades criando novos métodos e formas de trabalho." (CUNHA, 2003, p. 42).

Partindo dessa premissa, esta pesquisa busca contemplar a aproximação do papel social do bibliotecário e das bibliotecas, com ênfase nas minorias sociais, e principalmente nas pessoas trans, por meio de revisão da literatura e breve levantamento bibliográfico, além de evidenciar a competência em informação como vertente profissional de viés social.

A terminologia trans é descrita como um "guarda-chuva" sobre aqueles que perpassam pelas expectativas binárias convencionais de identidade ou expressão de gênero. Em síntese, a pessoa transgênero é aquela cuja identidade de gênero não corresponde ao seu sexo biológico atribuído no nascimento (PARENTS, FAMILIES, \& FRIENDS OF LESBIANS AND GAYS, 2008).

É importante ressaltar que a temática e seus itens correlatos são aferidos por pesquisadores não-especialistas em questões e experiências transgênero vividas, levando em consideração o respaldo da literatura, midiático e de conhecidos para estabelecer algumas suposições acerca. $\mathrm{O}$ fator propulsor do estudo consiste em estender a voz reprimida de tais pessoas, e não representálas, pois existe uma notável lacuna de estudos, pesquisas ou relativos feitos por elas, e não sobre elas. 
Justifica-se o estudo como parte inerente da função social e transformadora do bibliotecário(a), da biblioteca e da ciência, no apoio às pessoas trans e à população de lésbicas, gays, bissexuais, travestis, transexuais e transgêneros e demais $\left(\mathrm{LGBT}+{ }^{1}\right)$ em sua totalidade. É também dever dos profissionais da informação o trabalho de redução das opressões e barreiras impostas aos grupos minoritários.

\section{Pessoas trans na biblioteca: uma compreensão necessária}

Sob a acepção de Suess (2010), o termo trans abrange todas as pessoas que incorporaram uma identidade ou expressão de gênero diferente da designada ao nascer, incluindo nesse escopo pessoas transexuais, transgêneros, travestis, crossdressers, não gêneros, multigêneros, de gênero fluído, gênero queer e outras autodenominações relacionadas.

Tal definição reafirma a condição de termo "guarda-chuva", devido a sua grande abrangência e diversidade, assim como se observa a importância da autopercepção na identidade social dessa população. A identidade social é um autoconceito definido pelos seres a partir das características dos grupos nos quais estão inseridos, sendo que cada pessoa possivelmente se associa em determinados grupos sociais (SUESS, 2010).

No caso das identidades trans, tal grupo compreende a presença de corpos travestis, transexuais e outros que destoam da dicotomia homem/masculino e mulher/feminino; se apresentando em grupos de pertença considerados desviantes, anormais, excêntricos, fazendo parte de

[...] conjuntura populacional em vulnerabilidade social e econômica, devido ao preconceito que se constitui em torno destes sujeitos; assim como integram o grupo social de pessoas que, para terem acesso às transformações corporais que tanto reivindicam como condição indispensável para vivenciar a sua sexualidade e sua identidade, se submetem a tratamentos hormonais e à cirurgia de redesignação ou readequação genital. (SILVA; CERQUEIRASANTOS, 2014, p. 31-32)

Entretanto, apesar de integrarem tais conjunturas sociais, outro conceito que é necessário ser salientado para a compreensão da identidade social trans é o 
de identidade de gênero, relacionada ao autoreconhecimento que o indivíduo possui de si mesmo, diante dos padrões de gênero instituídos por instituições sociais. Tais indivíduos colocam em questão práticas sociais impostas nestes corpos como "estratégias de poder que supervalorizam a identidade masculina, branca e heterossexual, enquanto identidade sólida e referência confiável em detrimento do feminino." (SILVA; CERQUEIRA-SANTOS, 2014, p. 31-32).

É notório que desde os primórdios da humanidade, estamos acostumados a categorizar o que existe ao nosso redor. Pessoas, objetos, cores, enfim: interpretamos o mundo como um lugar pasteurizado, com vistas a torná-lo mais “palpável” ou menos complexo.

Para a população trans, em geral, lidar com o estereótipo de gênero, o estigma e o preconceito como sujeito divergente em relação a sua identidade converte-se no enfrentamento em situações cotidianas, consequência também da ausência de suporte/apoio social externo. Logo, as individualidades trans são consideradas "anormais" e, assim, suas identidades são alvo de estigmas, preconceitos e violências pelo fato de reivindicarem o direito ao reconhecimento enquanto mulheres (trans femininas), homens (trans masculinos) ou ainda como agêneros (genderless, não binário) e gênero fluido. (SILVA; CERQUEIRASANTOS, 2014).

$\mathrm{Na}$ contemporaneidade, as ressignificações sociais, políticas e econômicas estão ocasionando quebras de paradigma comportamentais, modificando as relações sociais em micro e macro esfera. Visto que essas mudanças, por vezes, são imperceptíveis aos envolvidos nessa dinâmica, há ocasionalmente benefícios e malefícios. (FARIAS; COSTA, 2017, p. 2).

E mais: as mudanças contínuas fomentam possíveis conquistas de novas formas de poder, em que o "domínio" cognitivo torna-se incentivador e mediador na transformação de realidades sociais, direcionando, por exemplo, o acesso e o uso da informação de forma consciente, impulsionando os indivíduos “[...] à conquista de seu espaço social, retirando-os da categoria de meros espectadores da realidade dos fatos." (FARIAS; COSTA, 2017, p. 2).

Uma vez que o padrão social da atualidade é predominantemente excludente e cada vez mais se proliferam as desigualdades sociais, econômicas, 
culturais e informacionais, as bibliotecas e unidades de informação são vistas como instituições protagonistas da educação e do livre acesso à informação, contribuindo para a diminuição da exclusão social (ORGANIZAÇÃO DAS NAÇÕES UNIDAS PARA A EDUCAÇÃO, A CIÊNCIA E A CULTURA, 2016).

O apoio cognitivo - e outros - às pessoas trans, em especial na infância e na adolescência, é basilar para prevenir situações de vulnerabilidade e risco, especialmente na desconstrução dos estigmas sociais e no auxílio colaborativo de projetos de vida, em um cenário no qual a emancipação, o respeito à individualidade e os direitos sociais possam ser restaurados na vivência. (SILVA; BEZERRA, QUEIROZ, 2015).

De acordo com Amendola, Oliveira e Alvarenga (2011), o apoio social apresenta-se como processo empático, o qual diz respeito a toda e qualquer informação ou auxílio vindo de terceiros, principalmente das pessoas ou grupos com os quais existe contato regular, produzindo efeito positivo para ambas as partes. Refere-se também ao apoio externo para receber amparo material, emocional ou afetivo em circunstâncias difíceis, bem como para se sentir valorizado nos grupos sociais nos quais está inserido (COSTA; DELL'AGLIO, 2009).

$\mathrm{O}$ apoio pode ser categorizado como emocional e afetivo - referente à qualidade e à sustentação dos laços, constatado nas manifestações de amor, de afeto e de confiança; informacional e instrumental ou material - decorrente da troca de informações e de ajuda na solução de problemas cotidianos e doenças, por exemplo; e como forma de interações positivas - na participação em ações de prazer e do bem-estar alheio (COSTA; DELL'AGLIO, 2009).

A apartação de apoio informacional, instrumental e/ou material também pode ser compreendida como pobreza na dimensão de informação e comunicação. Barja e Gigler (2006) discutem que essa linha de pobreza implica na capacidade básica para ser considerado membro efetivo da sociedade atual, a qual contém três componentes: ativos, informação e comunicação. 
Não obstante, as pessoas necessitam usufruir de um conjunto mínimo de ativos relacionados às tecnologias, saúde básica, educação, apoio social e capacidade produtiva para se exercer a cidadania. Devem ser aptos para trocar, receber e fornecer informações básicas sobre o mundo que lhes cerca e para comunicar-se por meio da análise dessas, seja sobre assuntos cotidianos, políticos, econômicos e outros (BARJA; GIGLER, 2006).

Muitas redes de apoio social/organizações de pessoas trans surgem a partir de contatos estabelecidos em locais de prostituição. Várias das atuais lideranças do movimento dessa população já gozavam de legitimidade e confiança por parte de outras semelhantes antes mesmo de comporem algum tipo de organização formal. Essa posição de liderança constituiu-se em função do papel que elas assumiram em uma rede de apoio social formada para lidar com problemas cotidianos, como o acesso a serviços de saúde e outros (CARVALHO; CARRARA, 2013).

Alçadas às margens da sociedade, as pessoas trans muitas vezes vêem na prostituição a única opção de sobrevivência e de rede de apoio social, que, consequentemente, é a porta de entrada para vulnerabilidades - seja em forma de Doenças Sexualmente Transmissíveis (DSTs), violência física ou outras adversidades, constituindo-se como um reflexo da transfobia ${ }^{2}$ (NOGUEIRA; AQUINO; CABRAL, 2017).

Apreendendo a concepção de "redes sociais" de Green (2000) como o acolhimento dos vulneráveis e marginalizados, a participação nas redes sociais de apoio é vital para o acolhimento e respeito externo e para florescer o sentimento de pertença e de direito ao seu lugar na sociedade; além da sensação de empoderamento frente aos ativos opressores persistentes em dificultar a realização de vontades pessoais (PERES, 2009).

No contexto da biblioteca como rede de apoio social, a Declaração de Direitos da Biblioteca (2008) da American Library Association (ALA), referente ao título Acesso a recursos e serviços da biblioteca independentemente do sexo, identidade de gênero, expressão de gênero ou orientação sexual apresenta diretrizes específicas às questões de gênero. Para a ALA, as bibliotecas e os 
bibliotecários devem ser veementemente contra os princípios opressores de materiais sobre qualquer tópico, incluindo sexo, identidade de gênero, expressão de gênero ou orientação sexual.

A declaração da então presidente da ALA, Julie Todaro, em oposição ao descaso do governo norte-americano de Donald Trump com a população trans nas escolas, atesta a premissa de solidariedade e missão social da instituição às questões inerentes:

\begin{abstract}
A decisão da administração Trump de revogar proteções importantes para os estudantes transgêneros não pode entrar em conflito com os valores fundamentais da comunidade bibliotecária e os princípios sobre os quais as bibliotecas são fundadas. Os estudantes transgêneros detêm o direito de utilizar o banheiro que esteja alinhado com sua identidade de gênero. [...] A ALA, seus membros, todos os bibliotecários e profissionais da biblioteca estão empenhados na diversidade, inclusão e respeito mútuo para todos os seres humanos, e trabalharemos incansavelmente para assegurar a representação total de todos os membros da sociedade. A ALA fornece banheiros neutros em suas conferências, e a instituição não realizará suas grandes reuniões em estados em que cotas de banheiro foram aprovadas. Estamos de acordo com nossos membros transgêneros, colegas, famílias e amigos, e apoiamos plenamente o trabalho da nossa mesa redonda de gays, lésbicas, bissexuais e transgêneros (GLBTRT), cujos membros continuam a liderar a luta para abolir a intolerância para toda a sociedade. A ALA trabalhará em estreita colaboração com todos os seus parceiros para a reintegração destas proteções, o mais rápido possível. (AMERICAN LIBRARY ASSOCIATION, 2017, doc. não paginado, tradução nossa).
\end{abstract}

Nessa significação, as bibliotecas têm a responsabilidade de apoiar as diretrizes específicas sobre pessoas trans e demais expressões de gênero. Elas estão intimamente ligadas ao ensino e ao desenvolvimento cognitivo e é importante que sejam e forneçam um espaço seguro aberto a todos. Isso vai além de designar um único banheiro como neutro de gênero - o que só mantém a questão como separada, mas igual. Trata-se da questão de direitos civis, e as bibliotecas devem estar na vanguarda para fazer mudanças positivas acontecerem (PYATETSKY, 2016).

Como Miller (2016) articula, “As vozes unidas das bibliotecas são um testemunho de até onde chegamos para instaurar uma política positiva e inclusiva para apoiar a ampla diversidade de experiência humana entre nós." 
(MILLER, 2016, doc. não paginado, tradução nossa). Devemos fazer da "sociedade livre" que afirmamos ter uma realidade para os socialmente marginalizados (MILLER, 2016).

Para Martin Garnar, bibliotecário, professor e atual presidente da Freedom to Read Foundation (organização afiliada à ALA), em entrevista à Crum (2017), promover um espaço acolhedor para os usuários trans da biblioteca é uma de suas principais responsabilidades. É importante encontrar esse tipo de experiência de boas-vindas, o que não inclui apenas ter livros e outros materiais que representem a amplitude da experiência trans, mas também oferecer toda a gama de serviços de biblioteca para essa população. Pode ser tão simples quanto colocar seus pronomes de tratamento em seu registro ou em sua assinatura de e-mail (CRUM, 2017).

Nessa significação, as bibliotecas são conhecidas há tempos como o lugar em que todos devem ser bem-vindos e que tópico algum deve ser censurado, sendo a biblioteca o "lugar perfeito" para sediar discussões sobre tópicos de abordagem complexa. Outrossim, é importante modelar o tipo de diálogo civil equitativo que se busca na sociedade, e as pessoas precisam de oportunidades para aprender a se relacionar com as diferenças existentes, de forma a encontrar pontos em comum e fomentar a empatia (CRUM, 2017).

Para pessoas que se autoidentificam como trans, ou qualquer outro tipo de identidade social que possua propensão ao estigma ou violência, a questão acerca da divulgação de informações sobre si mesmo é delicada. Quando dados identitários são compartilhadas - podendo resultar em discriminação, assédio ou violência -, há um grau de exposição indevido e danoso (THOMPSON, 2016).

Assim, é antiético que esse tipo de dados seja compartilhado por terceiros, a menos que se tenha certeza de que a pessoa em questão tenha divulgado tal explicação publicamente, com a intenção de que outras pessoas soubessem; caso contrário, se a informação foi compartilhada de maneira privada, deve-se divulgá-la somente com consentimento explícito, isto é, de forma ética (THOMPSON, 2016).

A divulgação e/ou a capacidade de uma pessoa trans permitir a exposição da sua identidade é deveras importante; o que faz da biblioteca e do 
seu quadro de funcionários, em totalidade, aptos para estabelecer alianças em prol de populações oprimidas, discriminadas e, de muitas formas, violentadas como resultado da percepção de outras pessoas sobre suas identidades e, em particular, identidades de gênero (THOMPSON, 2016).

\section{A competência em informação como prática social do bibliotecário}

Vista como atributo profíssional do bibliotecário para a "emancipação" cognitiva do indivíduo na sociedade, ter competência em informação significa desenvolver habilidades para auxiliar o indivíduo a assimilar a informação e exercer seus atributos como cidadão. Assim, a discussão sobre o desenvolvimento da competência em informação, no âmbito da vulnerabilidade social e das minorias sociais, é necessária para o suprimento das necessidades de informação (BAYLÃO, 2001).

O processo de desenvolvimento da competência em informação na sociedade envolve, entre outras habilidades, assimilar as contínuas mudanças tecnológicas. Não se limita apenas ao uso das tecnologias disponíveis, mas vai além e envolve práticas de informação que influenciam os campos pessoal, social e profissional (BRUCE, 2002).

A competência em informação é parte do processo educacional e, portanto, um dos direitos do ser humano. Em contrapartida, a cobertura dos programas governamentais e não-governamentais continua sendo, em geral, limitada às necessidades e à demanda efetiva, marginalizando as populações rurais, indígenas, afrodescendentes, migrantes, de pessoas com necessidades especiais e privadas de liberdade, mantendo e aumentando a exclusão, ao invés de reduzi-la (ORGANIZAÇÃO DAS NAÇÕES UNIDAS PARA A EDUCAÇÃO, A CIÊNCIA E A CULTURA, 2009).

No contexto brasileiro, ainda há poucos estudos sobre o desenvolvimento da competência em informação voltado às pessoas trans e à população LGBT+. Para Belluzzo (2018), as temáticas “Competência em Informação e Inclusão social e digital", "Competência em Informação e Cidadania e aprendizado ao longo da vida" e "Competência em Informação e diferentes 
grupos/comunidades" demonstram alguma preocupação, - ainda que embrionária - com focos de atenção considerados basilares e que envolvem as principais linhas de ação da competência em informação.

No entanto, tais temas mereciam maior interesse da área e dos seus profissionais, uma vez que apresentam uma trajetória histórica que possibilitou constatar que a noção de competência em informação sofreu alterações ao longo do tempo, em conformidade com as questões sociais. As possibilidades de aplicação da competência em informação não devem se restringir a programas de ensino, tampouco a atividades e espaços profissionais; é preciso perpassar a visão da simples elaboração de material instrucional e de apoio ao manuseio das tecnologias para a aprendizagem; pressupõe-se focalizar em abordagens sociais (inclusão, cidadania e inclusão digital), principalmente em países em desenvolvimento, como o Brasil (BELLUZZO, 2018).

Quanto às produções acadêmicas/programas brasileiros, tais temáticas ainda são igualmente irrisórias, conforme infere Belluzzo (2018), situação constatada também pelo breve levantamento bibliográfico realizado na Biblioteca Eletrônica Scielo, na Base de Dados em Ciência da Informação (BRAPCI) e no Google Scholar para esta pesquisa. Por conseguinte, essa lacuna assegura a necessidade de maiores estudos e pesquisas que possam consolidar as referidas áreas no contexto brasileiro, considerando a sua influência no acesso e uso da informação mediante mídias e tecnologias inovadoras.

Os impactos e benefícios tecnológicos na vida contemporânea são incontestáveis; porém, é sabido que grande parte da população ainda se encontra à margem da utilização consciente e plena desses recursos, necessitando de mediação adequada devido à complexidade das novas habilidades, além da existência de políticas públicas que possam garantir a informação para todas as pessoas (BELLUZO, 2018).

Apesar disso, paulatinamente alguns esforços estão sendo empreendidos: o projeto de extensão em andamento intitulado "Competência em informação da população LGBT+, por meio das dimensões técnica, estética, ética e política" é um deles. Coordenado pela professora Elizete Vieira Vitorino (líder do Núcleo de Estudos e Pesquisas sobre Competência em Informação - GPCIn) e contando 
com a participação de um doutorando e dois graduandos (um destes últimos é uma mulher trans), o referido projeto foi aprovado pela Pró Reitoria de Extensão da Universidade Federal de Santa Catarina (UFSC) em 2017 e a sua execução dá-se em parceria com a Associação em Defesa dos Direitos Humanos com Enfoque na Sexualidade (ADEH) (UNIVERSIDADE FEDERAL DE SANTA CATARINA, 2018).

Os objetivos dessa extensão almejam desenvolver a competência em informação da população LGBT+ da Grande Florianópolis por meio das dimensões técnica, estética, ética e política. Além disso, pretendem, em específico:

a) identificar as necessidades de informação da população LGBT+ com vínculo na ADEH;

b) compilar fontes de informação, com foco nas necessidades de informação da população LGBT+ com vínculo na ADEH;

c) realizar oficinas sobre o uso das fontes de informação selecionadas para a população LGBT+ com vínculo na $\mathrm{ADEH}$, com base nas dimensões técnica, estética, ética e política;

d) analisar a competência em informação desenvolvida pela população LGBT+ com vínculo na $\mathrm{ADEH}$, com base no modelo de Information Search Process (ISP), de Carol Kuhlthau.

Acredita-se que a tríade ensino-pesquisa-extensão se debruça na efetivação da cidadania: o reconhecimento da sociedade como plural e diversa, estendendo as teorias democráticas tradicionais e possibilidades de viabilizar meios para a inclusão social. Destarte, a aprendizagem ao longo da vida, pressuposto básico da competência em informação, manifesta-se como continuidade nas redes de apoio às minorias. (COACCI, 2015).

\section{O papel social do bibliotecário}

Se em priscas eras a missão do bibliotecário era a de guardião do livro, nos tempos atuais seu fazer profissional dirige-se a mudanças cada vez mais rápidas. Em conformidade com Cunha (2003), a profissão de bibliotecário é uma 
profissão de âmago social, de mediação e de contato, na qual as atividades são realizadas com o outro e para o outro.

Segundo Almeida Júnior (1997), “[...] a nossa verdadeira função social [...] não é apenas incentivar a leitura, mas trabalhar com a informação, levá-la àqueles que dela necessitam [...]” (ALMEIDA JÚNIOR, 1997, p. 91). O Código de Ética da International Federation of Library Associations and Institutions (INTERNATIONAL FEDERATION OF LIBRARY ASSOCIATIONS AND INSTITUTIONS, 2012) para bibliotecários e outros profissionais da informação corrobora tal entendimento quando define a Biblioteconomia como atividade ética de alto valor agregado ao fazer profissional com informações.

O papel das bibliotecas e bibliotecários, na contemporaneidade, é apoiar e aperfeiçoar o registro e a representação da informação e subsidiar o seu acesso. Os serviços informacionais de interesse social, cultural e de bem-estar econômico dizem respeito à responsabilidade social do bibliotecário (INTERNATIONAL FEDERATION OF LIBRARY ASSOCIATIONS AND INSTITUTIONS, 2012).

Mais especificamente a Seção 2 do referido código, Responsabilidades para com os indivíduos e para a sociedade, trata sobre o viés social da profissão, discorrendo sobre a premência do papel do bibliotecário e demais profissionais da informação ao impedimento da restrição da informação, assim como sobre os serviços prestados, que devem ser fornecidos para qualquer pessoa de qualquer faixa etária, nacionalidade, crença política, condição física ou mental, gênero, descendência, educação, renda, raça, religião, orientação sexual, entre outras particularidades (INTERNATIONAL FEDERATION OF LIBRARY ASSOCIATIONS AND INSTITUTIONS, 2012).

Na sociedade contemporânea, há certa relação paradoxal entre o excesso de informação e o grande número de "[...] pessoas desinformadas, não pela opção de não quererem fazer parte desse processo, mas porque se vêem privadas do direito de participação.” (JESUS, 2007, p. 3). A informação, para muitos, só é acessível se for gratuita e se oriunda de meios - sociais, políticos, físicos aproximativos das pessoas (GUEDES, 2011). 
Sendo assim, cabe refletir como o bibliotecário pode efetivar seu apoio aos movimentos sociais - principalmente às comunidades vulneráveis. Ser ou estar vulnerável significa, de certa forma, ter dificuldade de acesso à informação. Na sociedade atual, o senso crítico é fundamental para filtrar informações necessárias para o cotidiano. Produzir informação para disseminála é reconhecido como ato de inclusão social (DZIEKANIAK; ROVER, 2011) e compreender o mundo social e seus contextos faz parte da formação do homem.

De acordo com Silva (2011), “o indivíduo está ligado a outros por um fenômeno de dependência recíproca, de interdependência." (SILVA, 2011, p. 120), cuja assimilação consiste em entender seu espaço como pessoa e profissional, suas individualidades, subjetividades e as influências territoriais, sociais e informacionais presentes ao seu redor (MORIGI; SILVA, 2005).

Almeida Júnior (1997) aponta que a prática profissional bibliotecária parte do pressuposto de que todos são absolutamente iguais, para todos são oferecidas oportunidades semelhantes e todos os "usuários" são padronizados. É notória a inverdade deste apontamento, visto, pela experiência, que as "pessoas não são tão iguais como imaginamos" (ALMEIDA JÚNIOR, 1997, p. 100), e as oportunidades oferecidas para tais, seja na educação, na cultura, são variantes e discrepantes.

Neste panorama, Cury, Ribeiro e Oliveira (2001) afirmam que "o trabalho com as representações de determinado grupo social permite aprender, pelo conhecimento dos objetos sociais, o uso que dele fazem os indivíduos ou grupos." (CURY; RIBEIRO; OLIVEIRA, 2001, p. 2). A biblioteca é um espaço sociável de interação e de comunicação das pessoas e ato de sociabilidade infere na produção de conhecimento e na sua proliferação (MORIGI; SILVA, 2005).

Outro ponto de vista relativo à sociabilidade e ao trabalho com os grupos sociais diversos dá-se na participação política do bibliotecário. Sabe-se que uma grande parcela da sociedade desconhece seus direitos e, portanto, prossegue enraizada no lugar-comum da ignorância, da subalternidade (ALMEIDA JÚNIOR, 1997).

Por esse ângulo, Almeida Júnior (1997, p. 91) questiona: “[...] e o bibliotecário, onde entra nisso tudo?" e segue sua reflexão, inferindo que grande 
parte da classe bibliotecária acredita ser destituída de responsabilidade política, não tendo direito e/ou propriedade para interferir nesse contexto, visto que a relação política condiz apenas "entre o povo e os políticos" (ALMEIDA JÚNIOR, 1997, p. 91).

É justamente em detrimento dessa mentalidade que a "[...] população não nos reconhece como úteis socialmente [...].” (ALMEIDA JÚNIOR, 1997, p. 91): pelo fato da classe bibliotecária não reconhecer o papel social que é trabalhar com a informação, disseminá-la aos que necessitam e, por meio dela, permitir que a população conheça seus direitos, tenha como reivindicá-los e detenha a consciência social e política capaz de transformar toda a conjuntura sóciopolítica predominante (ALMEIDA JÚNIOR, 1997).

A população, logo, não reconhece a referida classe como socialmente útil, porque praticamente nada de significativo está sendo feito por ela. Serve-se aos interesses da minoria privilegiada que monopoliza o poder - os ditos opressores, que não querem a proliferação das informações e do conhecimento às massas. Ao trabalhar única e exclusivamente com os alfabetizados, colaborase com os que puderam estudar e amplia-se a diferenciação entre eles e os que a sociedade, por alguma circunstância, não permitiu que tivessem acesso ao conhecimento, à informação (ALMEIDA JÚNIOR, 1997).

O bibliotecário, como já dissemos, não é apolítico, neutro, imparcial. Como pode o bibliotecário se considerar imparcial se os materiais do seu acervo são parciais? Como pode o bibliotecário se considerar imparcial se a própria localização da biblioteca onde trabalha serviu a interesses políticos e que não exprimem a real necessidade da comunidade? Como pode o bibliotecário se considerar imparcial se aqueles que mais necessitam da biblioteca estão impossibilitados de fazer uso dela? (ALMEIDA JÚNIOR, 1997, p. 92).

A função política do bibliotecário consiste, de modo semelhante, na premência da atuação voltada às populações vulneráveis, carentes de informações, para quem uma postura "[...] apática, passiva e reacionária [...]" (ALMEIDA JÚNIOR, 1997, p. 92) do profissional e institucional será conivente com o partidário dominante.

Não basta espalharmos bibliotecas em cada quarteirão, em cada esquina. É preciso que o bibliotecário que atuar nessas bibliotecas 
seja um outro bibliotecário; é preciso que ele esteja consciente de sua real função social; é preciso que ele saiba que o seu trabalho pode e deve alterar pensamentos e comportamentos; é preciso que ele vá até a população, que ele procure o povo, que ele trabalhe com a comunidade. (ALMEIDA JÚNIOR, 1997, p. 92).

É importante que o fazer profissional/político do bibliotecário seja também direcionado à conscientização do papel do cidadão na resolução qualitativa de situações cotidianas. A partir de tal fazer, pode-se desenvolver o empoderamento individual, para que as ações realizadas sejam conduzidas pelo agir e pensar, indo além do gerenciamento de conflitos que se apresentam em variados contextos. Através do empoderamento individual, adquire-se o poder de escolher quais ações serão úteis para que se consiga tomar decisões baseadas em vivências anteriores e de que forma as ações futuras podem beneficiar os outros (FARIAS; COSTA, 2017).

Coindicente a isto, Garrafa (2005) discorre acerca de três instâncias recorrentes da bioética que podem ser aplicadas na presente discussão: empoderamento, libertação e emancipação.

De tradução livre e direta do inglês, empoderamento (empowerment) encontra-se com a noção de liberdade, na qual a sociedade deve apresentar uma postura de cumplicidade robusta e, desse modo, será possível erradicar a fome, a pobreza e as demais formas de iniquidade; o entendimento de empoderamento dos individuais - vulnerabilizados em virtude do processo histórico e de características culturais das sociedades em que se encontram - perpassa o todo social, atuando como elemento ativo no poder de decisão e propiciando sua inserção coletiva. O empoderamento estaria, assim, sedimentado na articulação inerente entre os diferentes grupos e segmentos (GARRAFA, 2005).

Esse processo é o que transfigura um mero aglomerado de seres em uma sociedade, conforme a visão de Durkheim (2007):

A sociedade não é simples soma de indivíduos, e sim sistema formado pela associação, que representa uma realidade específica com seus caracteres próprios. Sem dúvida, nada se pode produzir de coletivo se consciências particulares não existem; mas esta condição necessária não é suficiente. É preciso ainda que as consciências estejam associadas, combinadas, e combinadas de determinada maneira; é desta combinação que resulta a vida social e, por conseguinte, é esta combinação que a explica. Agregando-se, penetrando-se, fundindo-se, as almas individuais dão nascimento a 
um ser, psíquico se quisermos, mas que constitui individualidade psíquica de novo gênero. (DURKHEIM, 2007, p. 96).

Sob a ótica de Garrafa (2005), o que confere humanidade aos seres biologicamente identificados como humanos decorre de um processo coletivo, que se alimenta diretamente da produção e reprodução correntes dos significados atribuídos às práticas sociais. A ação social politicamente compromissada é aquela capaz de transformar a práxis pública.

$\mathrm{Na}$ Bioética de Intervenção, aponta-se o corpo como indicador para a intervenção ética. Identifica-se e incorpora-se a dimensão coletiva e o entendimento da pessoa como uma totalidade somática, na qual estão articuladas as dimensões física e psíquica, apresentando-se, de modo integrado, nas interrelações sociais e nas relações com o meio (GARRAFA, 2005).

Assim, o contexto de empoderamento estabelece a ponte entre as pessoas, cuja corporeidade ratifica o processo de produção e reprodução social, e a coletividade da qual elas são originárias. É explicitada a relação dialética entre reflexão e ação na incumbência singular e coletiva, dado o impacto que as escolhas das pessoas produzem na realidade A ideia de empoderamento, portanto, liga-se à noção de que as escolhas pessoais não podem ser julgadas com olhares míopes e estereotipados de autonomia (GARRAFA, 2005).

Se a desigualdade emerge no meio social, mediante as individualidades, ofuscá-la consiste em reconhecer a relação evidente entre autonomia e responsabilidade. A autonomia trata-se da devolutiva mútua "[...] aos desejos, necessidades e vontades da pessoa, como também no reconhecimento da interconexão entre os seres humanos e todas as formas de vida, assim como na responsabilidade existencial exigida frente a elas." (GARRAFA, 2005, p. 128).

A concepção de libertação encontra-se diretamente com o empoderamento. Conforme Garrafa (2005), utilizando como base a linha de raciocínio de Paulo Freire, nesse ponto é identificada a oposição entre o cativeiro - ou a privação do direito de escolha - e a libertação - o exercício verídico da autonomia. As pessoas, incumbidas de seus papéis como atores políticos, podem fazer com que suas ações tanto estabilizem como transmutem o status quo. 
Libertação, no paradigma da inclusão social, denota posição de poder e possibilita a tomada de posição nesse jogo de forças. A libertação direciona a condução da luta política para assegurar tal liberdade, e sua adesão manifesta a luta dos cidadãos que almejam ser e sentir-se socialmente incluídos em quaisquer contextos, a partir da consciência sobre as forças externas que os impedem e da ação concreta de resistência a elas (GARRAFA, 2005).

Ter consciência da realidade, conforme Freire (1979) reflete, é distanciar-se dela; possivelmente, é saber observar os fenômenos ocorrentes em ótica macro. Desse modo, mostra-se a conscientização e a realidade que vai além do pão e circo. O despertar para a conscientização leva-nos à terceira instância discorrida por Garrafa (2005): a emancipação. Emancipado é unicamente aquele que suprimiu sua dependência, que alcançou o seu domínio próprio e pode sustentar não somente a sobrevivência, mas garantir suas escolhas mediante o alcance desta. Portanto, uma pessoa emancipada é uma pessoa livre (GARRAFA, 2005).

A emancipação exprime alforria, independência, liberdade: o caminhar que se inicia com a libertação. O poder sobre si mesmo é o que defere a emancipação, tornando a pessoa imune às forças opressoras. Extinguir a dependência é pré-requisito para a emancipação, valendo tanto para a pessoa quanto para o Estado. É nessa apreensão que a emancipação se torna um poderoso mecanismo (competência) para orientar a luta pela libertação e para colocá-la na dimensão coletiva (GARRAFA, 2005).

Garrafa (2005) acredita que qualquer uma das três instâncias, empoderamento, libertação e emancipação - apesar de sentidos diferentes, sustentam o discernimento do fenômeno de inclusão social como um processo dinâmico que precisa ser edificado e levado à execução efetiva, objetivando a conquista da verdadeira justiça social para as pessoas.

Não obstante, é possível relacionar o empoderamento individual ao predomínio social da informação e do papel social do bibliotecário como motriz norteador. O poder social é visto como a relação entre dois agentes, sendo o agente principal o detentor do poder, e o secundário, o que é afetado por esse poder. O poder também é entendido como a capacidade de influência, e as 
relações de poder na sociedade representam uma mudança no pensamento sobre a competência em informação (COPE, 2010).

De algum modo, quando questões sociais são dadas pela interação, constituem-se novos caminhos para a efetivação do papel coletivo, realizando a inclusão e, consequentemente, o protagonismo social. Farias (2015) expõe que essa faceta do protagonismo faz do ser alguém pleno, assim como o possibilita agir nos processos decisórios, seja no consumo, na produção, na mediação ou em outras práticas sociais.

O protagonismo social faz da pessoa a principal transformadora de sua própria realidade, exercendo influência direta nas tomadas de decisões individuais ou coletivas. Aquele que é protagonista, então, também dá à sua própria realidade um novo significado (FARIAS; COSTA, 2017).

O protagonismo social está relacionado ao ato de empoderar, que é transformar a si mesmo e aos outros em protagonistas, é sair de uma condição de sujeição, é livrar-se do fardo de estar sujeito a uma subjetividade imposta que dita quem você é e como deve agir, é um processo criativo pelo qual pessoas e coletividades ampliam seu campo de ação [...]. (ASSOCIAÇÃO BRASILEIRA DE ENFERMAGEM, 2014, p. 16, grifo nosso).

Sendo o protagonista o ser consciente de sua função social e de sua capacidade de mudança da sociedade, ele busca instigar a capacidade de resolver conflitos e desafios cotidianos nos seus semelhantes. É o que pode acontecer com o bibliotecário - especialmente quando se trata do seu papel social - ao deparar-se com situações que exijam habilidades interpessoais e técnicas (FARIAS; COSTA, 2017).

O bibliotecário, ao empoderar-se dos processos que envolvem suas rotinas profissionais, torna-se assertivo: fornece auxílio conciso às demandas, aponta soluções que viabilizam a participação na sociedade de forma mais crítica e ativa, motiva a desconstrução dos papéis coadjuvantes de situações cotidianas. A atuação/intervenção do bibliotecário junto às demandas torna-o, por consequência, protagonista social (FARIAS; COSTA, 2017).

Consoante a isso, Almeida Júnior (1997) ressalta:

Nós precisamos de uma Biblioteconomia subversiva. Nós precisamos de uma Biblioteconomia guerrilheira, que subverta a 
ordem das atuais prioridades; que procure, busque, constantemente, os interesses populares, que esteja voltada para os oprimidos. [...] E os bibliotecários querem que esses indivíduos procurem a biblioteca. [...] A biblioteconomia está precisando de uma "teologia da libertação". Talvez, com ela, os bibliotecários passem a se interessar mais pelo povo, pelos carentes de informação, não de uma forma assistencialista, mas como um dever, uma obrigação social da profissão. (ALMEIDA JÚNIOR, 1997, p. 92-93).

Como "obrigação social" da profissão, deve-se trabalhar para fazer da biblioteca, em quaisquer instâncias, instituição aconchegante e segura. A possibilidade de criação de banheiros neutros em termos de gênero, do sigilo quanto aos dados cadastrais na instituição - ou até mesmo a opção de nãoidentificação de gênero - e a garantia de que todos os frequentadores da biblioteca serão tratados com decoro constituem funções sociais. Sempre que as necessidades da população trans forem avaliadas e identificadas, é substancial a inclusão de toda a população durante o processo (ALMEIDA JÚNIOR, 1997; AMERICAN LIBRARY ASSOCIATION, 2015).

Fundamentando-se na premissa da informação como alicerce do desenvolvimento cognitivo e social, e do(s) bibliotecário(s) como protagonista(s), constitui-se papel significativo na sociedade contemporânea. Logo, somente a pessoa trans tem discernimento e entendimento concreto de como é a vida trans e quais são as implicações de (sobre)viver sua existência (THOMPSON, 2012).

Dito isto, o papel social do bibliotecário é contemplado além de suas práticas tradicionais, revelando-se interventor na resistência ou interventor na mediação de espaços físicos, serviço de referência, aquisição de materiais, etc. Ao colaborar para a edificação dos direitos civis da população trans - de ser reconhecida e respeitada como se identifica -, esse apoio torna-se incondicional (THOMPSON, 2012)

A consciência de tornar a classe bibliotecária sensível não apenas à orientação sexual, mas também às questões de identidade de gênero também faz parte da missão social. A realização de capacitações ou workshops nas instituições faz-se necessária, principalmente ao lidar com questões íntimas e singulares, como, por exemplo, o uso dos devidos pronomes (THOMPSON, 2012). 
Nesse prisma, os serviços tradicionais da biblioteca, ao adequarem-se à realidade da população em pauta - seja nos serviços de referência presenciais e virtuais, na Disseminação Seletiva da Informação (DSI), nos estudos de usuários, no desenvolvimento de coleções, marketing e recursos virtuais -, tornam-se mecanismos potenciais na satisfação da demanda (THOMPSON, 2012).

Adequar o fazer profissional aos interesses das demandas - e das demandas potenciais - é o que deve se manter em voga. É preciso que o trabalho feito esteja atento às mudanças da sociedade e à transformação em razão dessas. É preciso questionar

[...] nossas verdades, nossos dogmas, pois só assim estaremos realmente avançando no sentido de darmos dignidade ao ser humano, o status de objetivo maior de nossos trabalhos; estaremos realmente avançando no sentido de propiciarmos condições para que todos possam exercer seu papel de cidadãos, e essa ser a prioridade de nossa atuação. Hoje, estamos sem objetivos claramente definidos; não sabemos nossa função na sociedade e, em consequência, o porquê de nossa existência enquanto profissionais. Por causa disso, buscamos, mesmo sem o saber, a nossa razão de ser dentro de nós mesmos, dentro de nossas técnicas, serviços, dentro da biblioteca. A resposta, com certeza, está fora dos nossos pressupostos e dogmas. A resposta está na sociedade, no usuário, no cidadão. (ALMEIDA JÚNIOR, 1997, p. 103-104).

Compreende-se que a classe em questão pode auxiliar na promoção do empoderamento, da liberdade e da emancipação por meio das práticas sociais, $a$ priori. Entretanto, cabe a postura profissional emergente de reflexão social e política, em primeira instância. A classe deve estar preparada para conciliar os conflitos e lidar com as diferenças humanas, sociais e cognitivas (FARIAS; COSTA, 2017).

Desse modo, as práticas sociais exercidas propiciam ao bibliotecário(a) a mudança de postura profissional e a busca por estratégias que possam contemplar diversas demandas, pois seu fazer profissional deve voltar-se cada vez mais ao empoderamento e ao protagonismo social na adesão de agente/ator principal durante sua atuação junto às demandas (reais e potenciais), buscando compreendê-las, conquistá-las e apoiá-las em quaisquer circunstâncias (FARIAS; COSTA, 2017). 


\section{Considerações finais}

A informação é fator primordial no desenvolvimento humano e social, e os bibliotecários e as bibliotecas constituem papel significativo na sociedade contemporânea. Somente a pessoa trans tem discernimento concreto de como é a sua vida e quais são as consequências de enfrentar todo o estigma existente.

Nesse cenário é que o papel social do bibliotecário(a) entra em prática: seu fazer profissional vai além de suas práticas tecnicistas. Seu papel como mediador é indiscutível, seja em espaços físicos, serviço de referência ou aquisição de materiais no desenvolvimento da competência em informação. $\mathrm{O}$ aprendizado ao longo da vida propiciará o fortalecimento intelectual e, como via de mão dupla, ao mesmo tempo em que se aprende, ensina-se e vice-versa. A luta pelos direitos das pessoas trans ocorre apenas para que elas sejam reconhecidas e respeitadas da forma como se identificam, sendo esse um direito humano básico.

Para Almeida Júnior (1997, p. 108), “A razão de ser da nossa profissão, o papel que apenas e tão somente ela desempenha na sociedade, não é considerada como razão para debates e discussões [...]" (ALMEIDA JÚNIOR, 1997, p. 108); e, no mesmo sentido, a Biblioteconomia por vezes é vista pela sociedade e pelo profissional da área como uma “[...] matéria vazia, absolutamente oca, revestida por uma tênue e transparente casca, prestes a se romper, deixando ainda mais invisível uma profissão que ninguém vê." (ALMEIDA JÚNIOR, 1997, p. 108).

Deve-se apreender que é fundamental a proatividade e visibilidade como virtudes profissionais para fazer do bibliotecário um "[...] agente de transformação, ou seja, uma peça com capacidade para modificar, alterar a sociedade." (ALMEIDA JÚNIOR, 1997, p. 109) para atingir o protagonismo social - do profissional e da sociedade (GARRAFA, 2005; FARIAS; COSTA, 2017).

O papel social bibliotecário é, indiscutivelmente, vivenciar, captar e buscar suprir as necessidades de informação do modo que lhe compete compreender o fenômeno, pois, no mundo social, se o habitat contribui para 
fazer o hábito, o hábito também contribui para fazer o habitat, por meio das interações sociais e dos estímulos envoltos. A aproximação de realidades distantes no mundo social viabiliza a aproximação social (BOURDIEU, 2003).

Cabe a nós, profissionais, pesquisadores ou equivalentes - pessoas, antes de titulações e funções - discernir sobre quais condutas profissionais adotar, no intuito de amenizar a falta de informação e as barreiras construídas pelo preconceito e opressão existentes. É importante ressaltar que as pessoas trans (T) têm particularidades mais densas em relação ao restante da população LGB+ e, por isso, necessitam de apoio substancial.

A biblioteca e as unidades de informação condizentes com a contemporaneidade devem ser criativas, inovadoras e livres de preconceitos para ter êxito ao lidar com as complexidades humanas e tecnológicas (BIRANVAND; SOHEILI; KHASSEH, 2015). A quinta lei da Biblioteconomia, de Ranganathan, determina: a biblioteca é um organismo em crescimento (RANGANATHAN, 2009). Crescimento relacionado à importância social e qualidade para aqueles que a usam e para aqueles que talvez a usarão. Crescimento mútuo nas relações institucionais/profissionais e, acima de tudo, humanas.

\section{Referências}

ALMEIDA JÚNIOR, Oswaldo Francisco de. Sociedade e Biblioteconomia. São Paulo: Polis, 1997.

AMENDOLA, Fernanda; OLIVEIRA, Maria Amélia de Campos; ALVARENGA, Márcia Regina Martins. Influência do apoio social na qualidade de vida do cuidador familiar de pessoas com dependência. Revista da Escola de Enfermagem da USP, São Paulo, v. 45, n. 4, p. 884-889, ago. 2011.

AMERICAN LIBRARY ASSOCIATION. Access to library resources and services regardless of sex, gender identity, gender expression, or sexual orientation. [S.1.]: ALA, 2008.

AMERICAN LIBRARY ASSOCIATION. ALAnews: ALA strongly protests rollback of protections for our nation's transgender students. Chicago: ALA, 2017. 
AMERICAN LIBRARY ASSOCIATION. Transgender-inclusive Library

Card Applications: issues and recommendations. [S.1.]: ALA, 2015.

ASSOCIAÇÃO BRASILEIRA DE ENFERMAGEM. Protagonismo da enfermagem no processo de cuidar: caderno de dicas. In: SEMANA BRASILEIRA DE ENFERMAGEM, 75., 2014, Brasília. Anais... Brasília: ABEN, 2014. p. 1-36.

BARJA, Gover; GIGLER, Björn-Sören. Pobreza digital: las perspectivas de América Latina y el Caribe. Qué es y cómo medir la pobreza de información y comunicación en el contexto Latinoamericano. [S. 1.]: DIRSI, 2006.

BAYLÃO, Raul Di Sergi. Um conceito operacional de minorias. Revista da Fundação Escola Superior do Ministério Público do Distrito Federal e Territórios, Brasília, v. 17, n. 9, p. 209-233, jan./jun. 2001.

BELLUZZO, Regina Célia Baptista. A competência em informação no Brasil: cenários e espectros. São Paulo: ABECIN, 2018.

BIRANVAND, Ali; SOHEILI, Faramarz; KHASSEH, Ali Akbar. Creativity of Librarians in Public Libraries: case study of public libraries of fars province (Iran). Library Philosophy and Practice, Lincoln, p. 1-17, 2015.

BOURDIEU, Pierre. A miséria do mundo. 5. ed. Petrópolis: Vozes, 2003.

BRUCE, Christine Susan. Information literacy as a catalyst for educational change: A background paper. [S.1.]: UNESCO, 2002.

CARVALHO, Mario; CARRARA, Sérgio. Em direito a um futuro trans?: contribuição para a história do movimento de travestis e transexuais no Brasil. Sexualidad, Salud y Sociedad, Rio de Janeiro, n. 14, p. 319-351, ago. 2013.

COACCI, Thiago. Do homossexualismo à homoafetividade: discursos judiciais brasileiros sobre homossexualidades, 1989 - 2012. Sexualidad, Salud y

Sociedad, Rio de Janeiro, n. 21, p. 53-84, dez. 2015.

COPE, Jonathan. Information literacy and social power. In: ACCARDI, Maria; DRABINSKI, Emily; KUMBIER, Alana. (Ed.). Critical Library Instruction: theories and methods. Duluth, Minnesota: Library Juice, 2010.

COSTA, Letícia Graziela; DELL'AGLIO, Débora Dalbosco. A rede de apoio social de jovens em situação de vulnerabilidade social. In: LIBÓRIO, Renata Maria Coimbra; KOLLER, Ś́lvia Helena (Ed.). Adolescência e juventude: risco e proteção na realidade brasileira. São Paulo: Casa do Psicólogo, 2009. p. 219-263.

CRUM, Maddie. Librarians across America are using their powers for political good. The Huffington Post, [S.1.], 2017. 
CUNHA, Miriam Figueiredo Vieira da. O papel social do bibliotecário.

Encontros Bibli, Florianópolis, v. 8, n. 15, p. 41-46, jan./jun. 2003.

CURY, Maria Catarina; RIBEIRO, Maria Solange Pereira; OLIVEIRA, Nirlei Maria. Bibliotecário universitário: representações sociais da profissão.

Informação \& Sociedade, João Pessoa, v. 11, n. 1, p. 1-8, 2001.

DURKHEIM, Émile. As regras do método sociológico. 3. ed. São Paulo:

Martins Fontes, 2007.

DZIEKANIAK, Gisele; ROVER, Aires. Sociedade do conhecimento:

características, demandas e requisitos. DataGramaZero, Brasília, v. 12, n. 5, out. 2011. Não paginado.

FARIAS, Maria Giovanna Guedes. Mediação e competência em informação: proposições para a construção de um perfil de bibliotecário protagonista.

InCID, Ribeirão Preto, v. 6, n. 2, p. 106-125, set. 2015.

FARIAS, Maria Giovanna Guedes; COSTA, Daysene de Araujo.

Empoderamento e protagonismo social no setor de referência de bibliotecas

universitárias. Encontros Bibli, Florianópolis, v. 22, n. 50, p. 1-14, set. 2017.

FREIRE, Paulo. Conscientização: teoria e pratica da libertação: uma introdução ao pensamento de Paulo Freire. São Paulo: Cortez \& Moraes, 1979.

GARRAFA, Volnei. Inclusão social no contexto político da bioética. Revista Brasileira de Bioética, Brasília, v. 1, n. 2, p. 122-132, 2005.

GREEN, James Naylor. Além do carnaval: a homossexualidade masculina no Brasil do século XX. São Paulo: Editora UNESP, 2000.

GUEDES, Roger de Miranda. Bibliotecas comunitárias e espaços públicos de informação. In: MOURA, Maria Aparecida (Org.). Cultura informacional e liderança comunitária: concepções e práticas. Belo Horizonte: UFMG, 2011. p. 75-79.

INTERNATIONAL FEDERATION OF LIBRARY ASSOCIATIONS AND INSTITUTIONS. Código de ética da IFLA para bibliotecários e outros profissionais da informação. [S.1.]: IFLA, 2012.

JESUS, Marisa S. de. Implantação de bibliotecas comunitárias do estado da Bahia. In: ENCONTRO NACIONAL DE ENSINO E PESQUISA DA INFORMAÇÃO, 7., 2007, Salvador. Anais... Salvador: UFBA, 2007. p. 1-7.

JESUS, Jaqueline Gomes de. Orientações sobre Identidade de Gênero: conceitos e termos. 2. ed. rev. e ampl. Goiânia: SerTão, 2012.

LGBT+. In: URBAN Dictionary. [S.1.: s.n.], 2014. 
MILLER, Rebecca T. Defending Inclusion. Library Journal, [S.1.], 26 abr. 2016.

MORIGI, Valdir José; SILVA, Magali Lippert da. Paradigma tecnológico e representações sociais dos bibliotecários sobre seu perfil e suas práticas no contexto da sociedade da informação. Informação \& Sociedade, João Pessoa, v. 15, n. 1, p. 123-145, jan./jun. 2005.

NOGUEIRA, Sayonara Naider Bonfin; AQUINO, Tathiane Araújo; CABRAL, Euclides Afonso. Dossiê: a geografia dos corpos das pessoas trans. [S.l.]: Rede Trans Brasil, 2017.

ORGANIZAÇÃO DAS NAÇÕES UNIDAS PARA A EDUCAÇÃO, A CIÊNCIA E A CULTURA. Educação e aprendizagem para todos: olhares dos cinco continentes. Brasília: UNESCO, 2009.

ORGANIZAÇÃO DAS NAÇÕES UNIDAS PARA A EDUCAÇÃO, A CIÊNCIA E A CULTURA. Media and information literacy: reinforcing human rights, countering radicalization and extremism. Paris: UNESCO, 2016.

PARENTS, FAMILIES AND FRIENDS OF LESBIANS AND GAYS.

Welcoming our trans family and friends: a support guide for parents, families and friends of transgender and gender non-conforming people. [S.1.]: PFLAG, 2008.

PERES, Wiliam Siqueira. Cenas de exclusões anunciadas: travestis, transexuais, transgêneros e a escola brasileira. In: JUNQUEIRA, Rogério Diniz (Org.).

Diversidade sexual na educação: problematizações sobre a homofobia nas escolas. Brasília: MEC, 2009. p. 235-263.

PIRES, Erik André de Nazaré. O bibliotecário como agente transformador social: sua importância para o desenvolvimento da sociedade informacional através da disseminação da informação. In: ENCONTRO REGIONAL DE ESTUDANTES DE BIBLIOTECONOMIA, DOCUMENTAÇÃO, CIÊNCIA E GESTÃO DA INFORMAÇÃO, 15., 2012, Juazeiro do Norte. Anais eletrônicos... Juazeiro do Norte: EREBD, 2012. p. 1-15.

PYATETSKY, Julia. Do not go gentle into that gender neutral bathroom. Public Libraries Online, Chicago, 07 jun. 2016.

RANGANATHAN, Shiyali Ramamrita. As cinco leis da Biblioteconomia. Brasília: Briquet de Lemos Livros, 2009. 336 p.

SILVA, Ana Claudia Perpétuo de Oliveira da. A interação com o entrevistado na coleta de narrativas para a composição do Discurso do Sujeito Coletivo: vivências de pesquisadora. ACB, Florianópolis, v. 17, n. 1, p. 118-134, dez. 2011. 
SILVA, Bruno de Brito; CERQUEIRA-SANTOS, Elder. Apoio e suporte social na identidade social de travestis, transexuais e transgêneros. Revista da Sociedade de Psicoterapias Analíticas Grupais do Estado de São Paulo, Ribeirão Preto, v. 15, n. 2, p. 27-44, dez. 2014.

SILVA, Rodrigo Gonçalves Lima Borges da; BEZERRA, Waldez Cavalcante; QUEIROZ, Sandra Bomfim de. Os impactos das identidades transgênero na sociabilidade de travestis e mulheres transexuais. Revista de Terapia Ocupacional da Universidade de São Paulo, São Paulo, v. 26, n. 3, p. 364372, set.-dez 2015.

SUESS, Aimar. Análisis del panorama discursivo alredor de la despatologizaçãotrans: procesos de transformación de los marcos interpretativos en diferentes campos sociales. In: MISSÉ, Miquel; COLL-PLANAS, Gerard (Ed.). El género desordenado: críticas en torno a la patologización de la transexualidad. Madrid: EGALES, 2010.

THOMPSON, Kelly J. More than a name: a content analysis of name authority records for authors who self-identify as trans. Association for Library Collections \& Technical Services, [S.1.], v. 60, n. 3, p. 140-155, jul. 2016.

THOMPSON, Kelly J. Where's the "T"?: improving library service to community members who are transgender-identified. B Sides: Journal of the University School of Library and Information Science, Iowa, p. 1-17, 2012.

UNIVERSIDADE FEDERAL DE SANTA CATARINA (UFSC). Pró Reitoria de Extensão. Catálogo de Extensão 2018. Florianópolis: PROEX/UFSC, 2018, p. 46.

\title{
Librarian's social role to the trans people: theoretical approaches
}

\begin{abstract}
This paper analyzes, through a literature review, the librarian's and library's social role for trans people. It emphasizes information literacy as a social practice of the librarian, as well as points out the inexpressiveness in the Brazilian context of the initiatives aimed at the trans population and also lesbian, gay, bisexual and other populations. It also reaffirms the need to participate, based on their professional practices, in the political, socioeconomic, informational and resistance progress of the minority classes, pointing to social protagonism, empowerment, freedom and emancipation as necessary factors for personal, professional and of individuals. As a result of the study, it is pointed out the urgency of political librarian adherence to social minorities, focusing on social approaches (inclusion, citizenship and digital inclusion), especially in developing countries, such as Brazil. It is concluded that the librarians social role should be able to experience, capture and seek information needs in their own way, just as libraries and contemporary information units need to be
\end{abstract}


creative, innovative and free of prejudice, aiming to successful in dealing with human and technological complexities.

Keywords: Librarian. Library. Trans people. Social minorities. Information literacy.

Recebido: 06/03/2018

Aceito: $19 / 06 / 2018$

1 “O + representa os inúmeros outros grupos de minorias sexuais e de gênero que tornariam o acrônimo muito longo para uso prático." (LGBT+, 2014, doc. não paginado). Há controvérsias quanto ao uso, porém atesta-se que muitas ONGs e estudiosos aderiram à sigla LGBT.

2 Segundo Jesus (2012), transfobia é o "preconceito e/ou discriminação em função da identidade de gênero de pessoas transexuais ou travestis. Não confundir com homofobia, [...] [que é o] [...] medo ou ódio com relação a lésbicas, gays, bissexuais e, em alguns casos, a travestis, transexuais e intersexuais, fundamentado na percepção, correta ou não, de que alguém vivencia uma orientação sexual não heterossexual." (JESUS, 2012, p. 29). 